\title{
Palmyra: From War and Destruction to Rehabilitation
}

\author{
Maamoun Abdulkarim
}

\begin{abstract}
Palmyra is one of the most important cities on the World Heritage List; the city is distinguished by its ancient history, its vast site, and its archaeological buildings dating back mainly to the Roman era. It was famous for being the city of caravans and the important point of contact between East and West. It played an important political, economic, and cultural role during its history. This city is occupied by ISIS in 2015 and 2016, where they destroyed many important buildings such as temples, tower tombs, the Arc de Triomphe, part of the front of the theater, the destruction of dozens of statues in the National Museum, etc. In this research, we talk about the importance of this city, the damages that were caused to it, what are the procedures of rescue and documentation work, and our vision to providing a coherent framework and action plan to preserve the archaeological site, starting with repairs, protection, and restoration and ending with rehabilitation by setting short-, medium-, and long-term plans. Our plans of rehabilitating the ancient city of Palmyra will be based on international scientific standards approved by international organizations, such as the UNESCO, ICOMOS, and ICCROM.
\end{abstract}

Keywords Palmyra $\cdot$ History $\cdot$ Archaeology $\cdot$ Destruction $\cdot$ Rescue $\cdot$ Rehabilitation

\section{Introduction}

During the first three centuries AD, Palmyra, the Pearl of the Desert, experienced an economic and political boom, reflected in its architectural, urban, and artistic development. It was also manifested in the city's classical grid-plan, with its colonnaded

Published jointly by the United Nations Educational, Scientific and Cultural Organization (UNESCO), 7, place de Fontenoy, 75007 Paris, France, the UNESCO Office in Kabul, ICON Compound, Supreme Road, Off Jalalabad Road, PD 9, Kabul, Afghanistan, and Springer Nature Switzerland AG, Gewerbestrasse 1, 6330 Cham, Switzerland.

M. Abdulkarim ( $ه)$

General - Director of Antiquities \& Museums, Damascus, Syria 


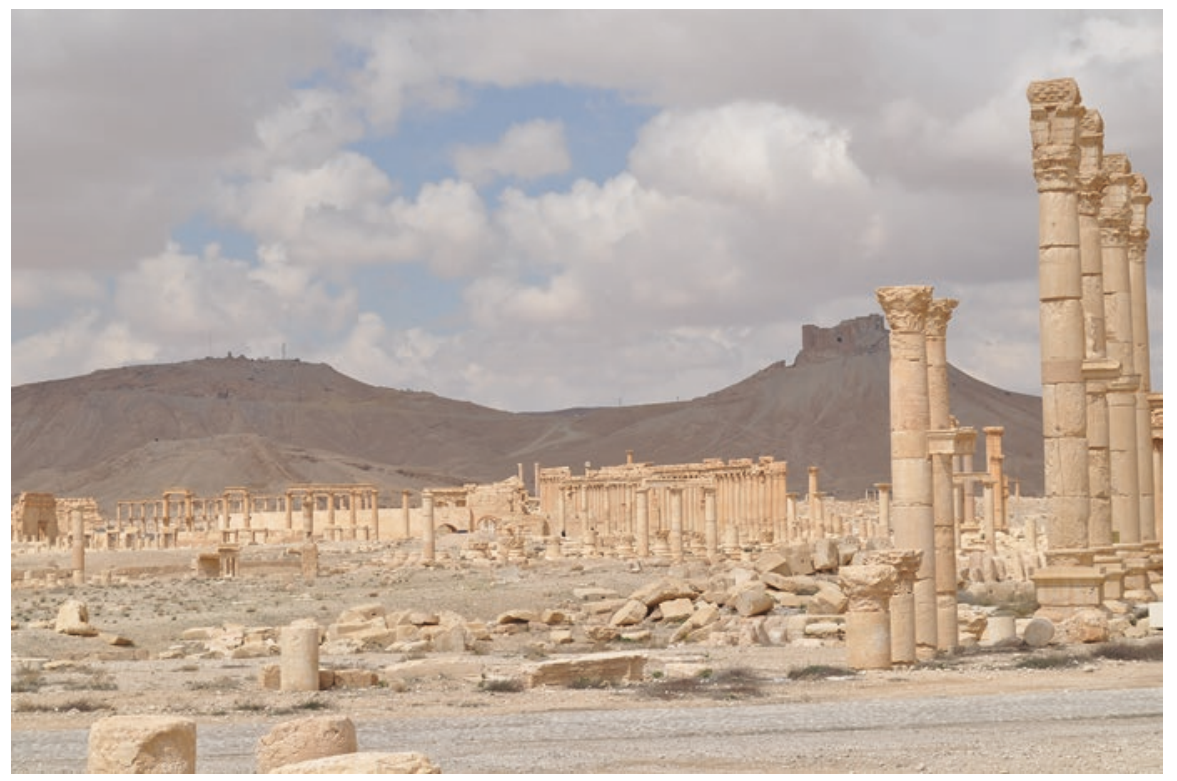

Fig. 1 Palmyra general view

streets and porticos giving the city a special charm. Several notable religious structures were built, such as the Temple of Bel, the Temple of Baalshamin, the Temple of Nabu, the Temple of al-Lāt, and others. In addition, the city was marked with its unique and well-designed funerary architecture. Public buildings in Palmyra included the Roman Theater, the Agora, the Baths, and the Camp of Diocletian, to name but a few (Fig. 1).

Palmyrene sculpture was distinguished by its splendor and the richness of its decorative and artistic elements, which painted a clear picture of the Palmyrene people. That was embodied in their clothing and jewelry as well as the GrecoRoman and Parthian influences. The Palmyrene art, sculpture in particular, however, retained its local identity and evolved into an artistic trend according to researchers and scholars who have worked at the site for years.

Palmyra, under Queen Zenobia, grew in importance in the third-century AD and played a strategic role in the relations between the Roman Empire and the Parthian and later Sasanian Empire. It defied Rome and declared its independence from the Roman Empire. Palmyra was also a key caravan stop linking the East with the West and represented a fusion of western and eastern arts.

ISIS' occupation of the city of Palmyra in May 2015 led to a real tragedy that struck a great civilization. Deliberate destruction and looting of cultural heritage occurred on a large scale during their control of the city.

The fall of Palmyra, a World Heritage Site, has had a dangerous impact on the Syrian archeological heritage. After the terrorist group known as ISIS entered the city and occupied it, the fate of this historic city, which has a special place in world heritage, drifted toward the unknown. This is a real tragedy for a civilization that 
deserves to be protected in every way possible, particularly for the fact that it contributed important cultural achievements in several fields to humanity. It also embodied, for centuries, a link between the East and West, becoming one of the main cities that hosted caravans during the Roman era and gaining fame for its breadth, diversity, and the multiplicity of its buildings that included temples, theaters, etc.

The situation in the spring of 2015 was characterized by an escalation of events in many areas in Syria. Armed groups gained control over Idlib and Bosra in late March, 2015, and the fate of hidden museum collections became unknown, especially after the expulsion of the staff of Idlib's Department of Antiquities. Thus, the DGAM communicated with the local community in order to protect the antiquities in Idlib, and it succeeded in keeping the staff working in the city of Bosra in order to keep the ancient city neutral and safe from vandalism and looting. The DGAM also transported the remainder of the artifacts in other museums in Deir ez-Zor, and 30,000 artifacts were finally transported to a safe place after documenting and packing them. It did the same with other museums such as those in Aleppo, Homs, Hama, Daraa, etc. Concerning the Museum of Palmyra, we worked determinedly to transport the artifacts from the museum to Damascus after the bitter experience we had had in Idlib, not knowing that the city would be occupied by ISIS in about a month and a half. Hence, from the beginning of the month of April, warehouses were opened and the artifacts taken out and packaged in boxes in preparation for their transport to Damascus in order to preserve them. This was an important step to take, especially for the fact that the Museum of Palmyra was deemed one of the most important museums in Syria for the massive amounts of statues, dating back to the Roman era, it housed.

The DGAM had managed before the fall of Palmyra to save more than 400 statues and hundreds of artifacts that had been moved to safe locations, as hundreds of artifacts and statues were packed in storage boxes and taken to Damascus. However, the sudden arrival of ISIS terrorists in Palmyra made it impossible to evacuate large statues as well as a few severely damaged heads of statues fixed on the walls of the museum halls.

The terrorist organization had destroyed tens of artifacts that were displayed on the ground floor using hard tools such as hammers. The shrapnel was dispersed all over the museum among shattered glass and broken furniture. Fortunately, the ruined statues are not completely destroyed. The Lion of al-Lāt, dating back to the first century AD, was smashed.

The museum building was badly damaged, too, due to clashes; the ceiling, doors, and windows crashed in many places; and pieces of stone were scattered everywhere mixed with pieces of broken statues. It is worth noting that the militants converted the museum into a court and jail, where they interrogated archaeologist Khaled al-Asaad and others (Fig. 2).

They also destroyed a number of archaeological buildings, including the temples of Bel Fig. 3) and Baalshamin (Fig. 4), the Monumental Arch, and some tower tombs (Fig. 5). They carried out clandestine excavations at the archaeological site and committed murders, such as the brutal murder of Khaled al-Asaad. 


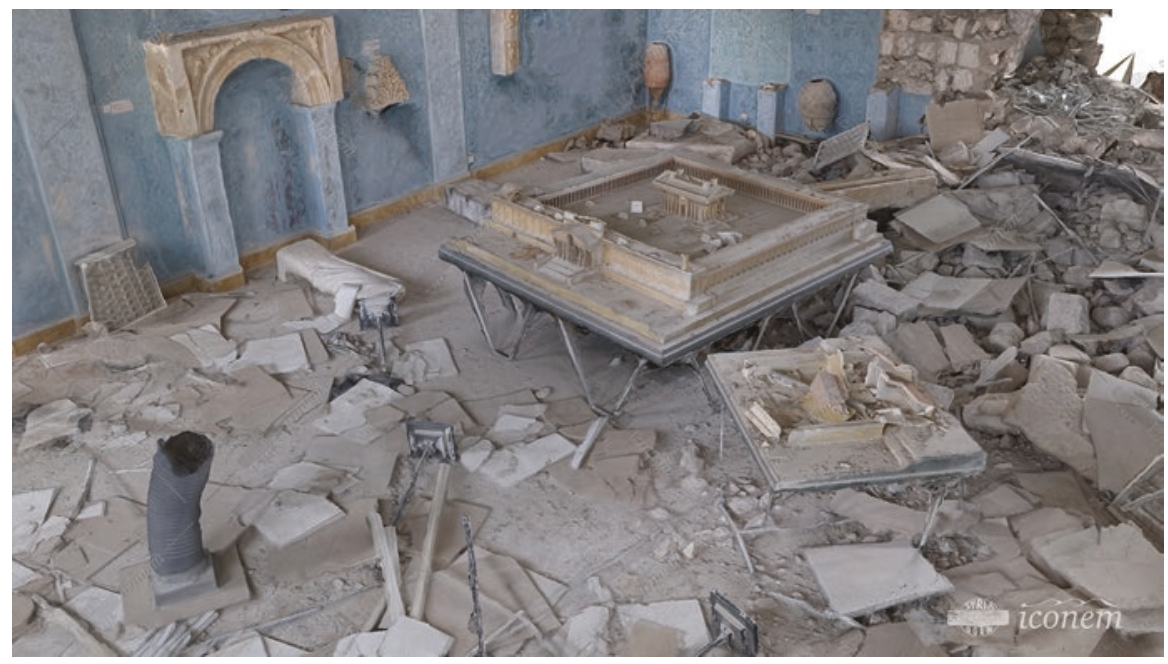

Fig. 2 Museum Palmyra, ( ICONEM

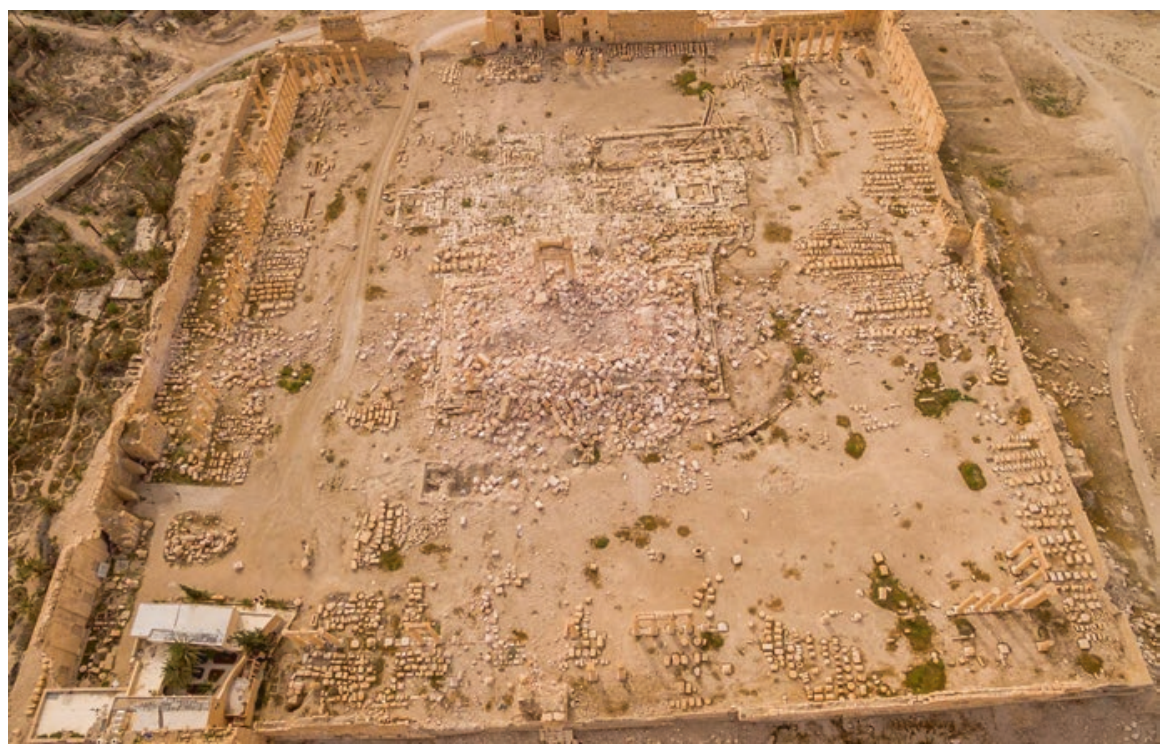

Fig. 3 Palmyra - Temple of Bel - C ICONEM

We remember well how people worldwide were moved and how they reacted passionately toward these events, which was evident in the hundreds of news items spread in global media platforms, which had a significant role in triggering people's emotions all over the world. For the first time since the onset of the crisis in 2011, we felt that we were no longer alone in defending an important part of the world 


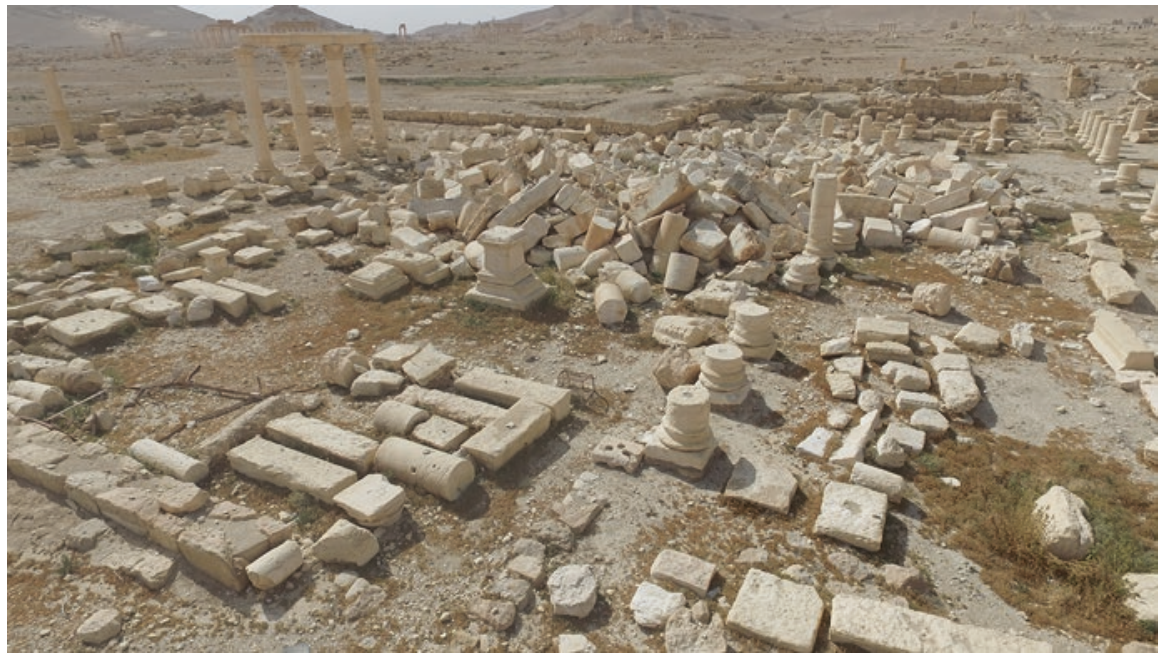

Fig. 4 Temple Baalshamin

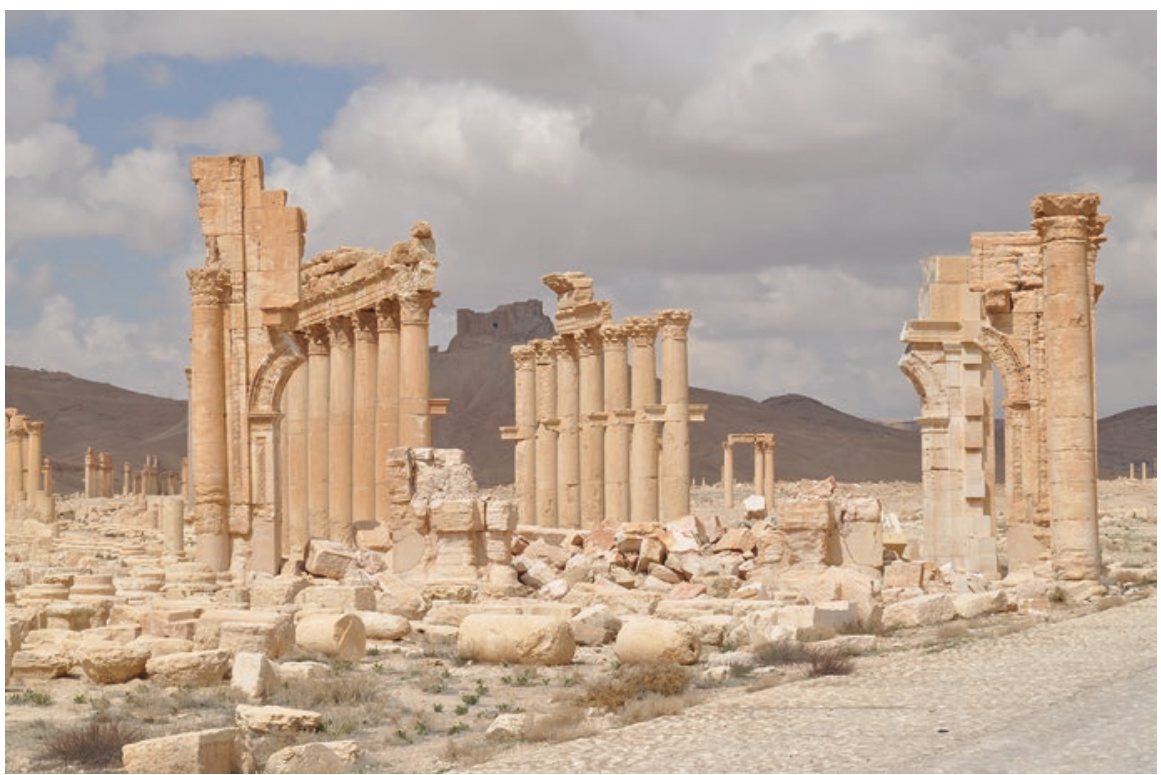

Fig. 5 Palmyra Triumph Arch 16 March 2017

culture heritage in Syria. For several years before the fall of the city of Palmyra, we, researchers and employees in the country, had undergone bitter experience defending the Syrian heritage, since we, due to the Syrian crisis, had been abandoned by many except for international organizations such as the UNESCO, ICOMOS, and ICCROM in Italy and Sharjah, the Interpol, the World Monuments Fund (WMF) in 
New York and its branch in London, the Arab Regional Centre for World Heritage in Bahrain, cultural associations such as the Associazione Priorita Cultura in Rome, European universities and international archeological institutes, and others. Throughout the years of the crisis, we have been visited by only few researchers, but the tragedy of Palmyra was a new occasion to push many people to embark with us on a search for new horizons of cooperation to ensure the success of the projects of the Syrian DGAM and save what could be saved of the Syrian heritage.

World press has indeed played a pivotal and positive role in most countries to inform the international community of the truth of the cultural massacres being committed against the Syrian heritage by antiquities gangs and ideological extremism. Hundreds of journalists increasingly visited Syria during 2015 and 2016, and we have always reminded everyone not to abandon us in this cultural battle we lead to protect the Syrian heritage for all Syrians irrespective of any ideological differences among them. Also, we have always encouraged everyone to defend this heritage, which has made all Syrians unite forces to defend their identity and shared memories. This stems from our conviction that the Syrian crisis will end 1 day and peace will prevail all throughout Syria, fixing what has been destroyed during the crisis, but every loss against our heritage will be irrevocable because it touches the history of this nation and its culture.

\section{The Liberation of the City and Measures Taken by the DGAM}

Palmyra remained under ISIS' control for 10 months which were full of destruction and under the threat of new tragedies until it was freed on 27 March 2016, ending a page of the black history the city experienced.

The Syrian government managed to reclaim the city, and in early April 2016, we were able to enter the site and examine the museum. When we entered the place, the museum looked in a miserable state. It had suffered major damage in its constructional structure, especially on the second floor and in the halls of the museum on the first floor, and the wreckage of artifacts and statues was all over the place.

The rescue work plan, carried out over a span of 60 days by the national team in cooperation with Polish experts from the University of Warsaw, relied on many actions taken, such as cleaning work; emergency rescue procedures for the building, museum holdings, and debris in all the halls of the museum; and sifting the debris to collect as many broken pieces of artifacts that were destroyed or damaged as possible, in addition to carrying out an inventory and rapid documentation of the museum pieces. The terrorist organization had destroyed around 200 archeological artifacts that were displayed on the ground floor using hard tools such as hammers. The shrapnel was dispersed all over the museum among shattered glass and broken furniture. Fortunately, the ruined statues are not completely destroyed. The Lion of al-Lât, dating back to the first century $\mathrm{AD}$, was smashed; however, the pieces are still in their place, along with the pieces of the head of the Greek goddess Athena. 

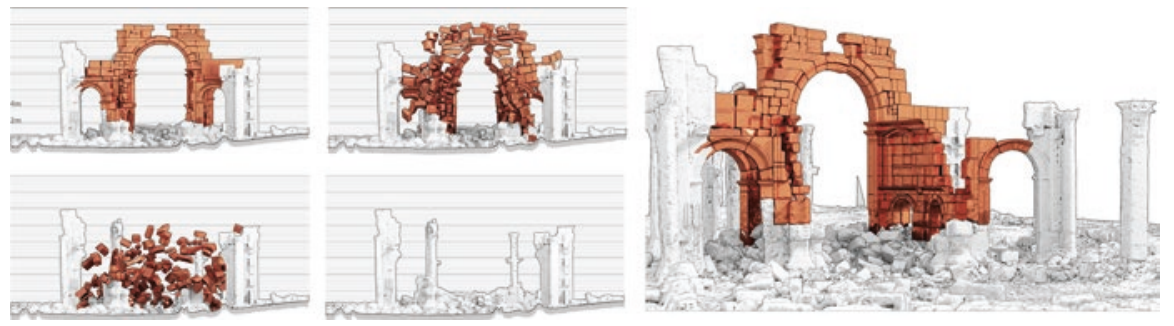

Fig. 6 Palmyra Triumph Arch Reconstitution - (C) ICONEM

As for the lower floor of the museum, the statues were dispersed in all its halls. In the meantime, a supportive team of engineers and technicians, made up of 90 members coming from Damascus and Homs, identified and assessed the risks (threats that affected the museum and its collections) within the halls and storage area. Also, an emergency intervention was carried out within the museum building by closing the damaged areas and locking the doors. The living conditions of the work team there were harsh, with no electricity or food as a result of the lack of infrastructure and basic services within the city of Palmyra, in addition to the lack of local residents most of whom were forced to flee.

To identify the amount of damage and document it, and to record the state of the site, the team used a 3D documentation process in collaboration with ICONEM (a French architectural firm based in Paris and run by Mr. Yves Ubelmann). This mission aimed at documenting the state of the archeological site and the museum immediately after liberating the city to provide accurate documents for experts and scientists that assist in the process of rehabilitation before any intervention or cleaning of the site (Fig. 6).

Fortunately, we made a decision to transport more than 400 statues and hundreds of artifacts that had been moved to safe locations, as hundreds of artifacts and statues were packed in storage boxes and taken to Damascus. However, the sudden arrival of ISIS terrorists to Palmyra made it impossible to evacuate large statues as well as a few severely damaged heads of statues fixed on the walls of the museum halls. This is intended to take place under the supervision of Syrian and foreign experts, particularly those who have worked at the site for decades. In addition, the restoration of the damaged statues will be funded by UNESCO. At the end of our work, after the first liberation of the city, the museum was completely emptied, and everything was transferred to Damascus and Homs.

\section{The Second Fall of Palmyra on 11 December 2016}

ISIS militant groups reoccupied the city of Palmyra on 11 December 2016, forcing us to experience another shock as we are sure they are going to destroy other buildings and structures in the same way they destroyed significant monuments when they took the city for the first time. This time, they demolished a tetrapylon and the 
façade of the Roman theatre. We have also started to witness some of their criminal and destructive acts in the ancient city, which lives critical moments and a bleak nightmare, while awaiting its second liberation, which, we hope, will be soon.

Thus, within the framework of a culture war independent from any political nature, we aspire to see some international action aimed at rescuing the city from a potential calamity. This is owing to the fact that liberating Palmyra means rescuing one of the key constituents of world civilization from destruction and damage. Besides, we are positive that international and foreign policies change; nevertheless, heritage remains as a unifying factor and a collective identity for all Syrians, as well as a reconciliation project and a world legacy shared by all.

\section{The Second Liberation of Palmyra on 2 March 2017}

On March 2, the city was liberated again and we were able to enter the site. ISIS destroyed the stage backdrop of the second-century theater which suffered sustained damage along with the tetrapylon, a cube-shaped ancient Roman monument that sits in the middle of the colonnade road that leads to the theater, only 4 of the 16 columns of the tetrapylon remain standing.

\section{Vision}

The national strategy for protecting and rehabilitating the archaeological site of Palmyra is looking forward to preserving the archaeological heritage as a source of valuable and comprehensive environmental, economic, social, and political renewal. This will contribute to improving the quality of life and the environment in the local community.

The main objectives of this plan are the following: (a) identifying, protecting, and rehabilitating the monumental archaeological heritage which was damaged by the perpetrations of the terrorist organization ISIS; (b) promoting restoration projects and the strategy of maintenance and rehabilitation; (c) implementing all the necessary measures to protect the archaeological site in the best conditions possible and in accordance with the principles and methods of the restoration of exceptional values; (d) ensuring the participation of the local community in the stages of the plan; (e) providing decision-makers and the public opinion with the requirements of the project in order to have a wide range of participation of stakeholders and international organizations through financial and technical contributions; and (f) in addition providing a coherent framework and action plan to preserve the archaeological site, starting with repairs, protection, and restoration and ending with rehabilitation by setting short-, medium-, and long-term plans. Our plans of rehabilitating the ancient city of Palmyra, a World Heritage Site since 1980, will be based on 
international scientific standards approved by international organizations, such as the UNESCO, ICOMOS, and ICCROM.

Finally, we, the staff of the DGAM, comprised of almost 2500 employees including architects, engineers, and archaeologists, are determined to defend this world heritage notwithstanding the war and its life-threatening atrocities. We have also set aside our political differences and remained united all over Syria, whether in the government-held areas or nongovernment-controlled ones. This is because we have opted to stand against the division of our heritage and stressed that Syria has a unique heritage that brings all Syrians together with no exception. Our efforts were successful as we managed to transport more than $90 \%$ of the holdings of the museums to safe locations in Damascus. As for the artifacts preserved in some of the other museums, including Idlib and Bosra, they are still safe thanks to the local community and its elite as well as our employees, who still report for duty. We hope that these efforts shall eventually be crowned with victory for all Syrians and the international community.

Hence, we believe that as our specialist and experienced colleagues and friends stand by us in such dire circumstances, obstacles impeding our rescue mission of this human heritage shall fade away.

The opinions expressed in this chapter are those of the author(s) and do not necessarily reflect the views of the UNESCO, its Board of Directors, or the countries they represent.

Open Access This chapter is licensed under the terms of the Creative Commons AttributionShareAlike 3.0 IGO License (https://creativecommons.org/licenses/by-sa/3.0/igo/), which permits use, sharing, adaptation, distribution, and reproduction in any medium or format, as long as you give appropriate credit to UNESCO, provide a link to the Creative Commons licence and indicate if changes were made. If you remix, transform, or build upon this chapter or a part thereof, you must distribute your contributions under the same licence as the original. This publication is also available at the UNESCO Open Access Repository: https://unesdoc.unesco.org/

The designations employed and the presentation of material throughout this publication do not imply the expression of any opinion whatsoever on the part of UNESCO concerning the legal status of any country, territory, city or area or of its authorities, or the delimitation of its frontiers or boundaries.

The authors are responsible for the choice and the presentation of the facts contained in this chapter and for the opinions expressed therein, which are not necessarily those of UNESCO and do not commit the Organization. 